\title{
Utilization of Lightweight Materials Made From Coal Gasification Slags
}

\author{
Quarterly Report \\ March 1 - May 31, 1998
}

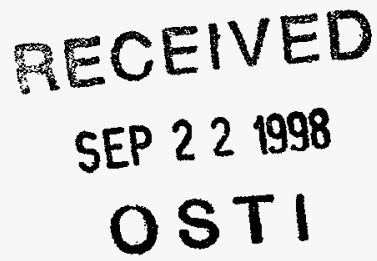

Work Performed Under Contract No.: DE-FC21-94MC30056

For

U.S. Department of Energy

Office of Fossil Energy

Federal Energy Technology Center

P.O. Box 880

Morgantown, West Virginia 26507-0880

By

Praxis Engineers Inc.

852 North Hillview Drive

Milpitas, California 95035

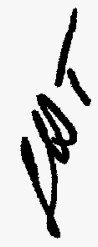




\section{Disclaimer}

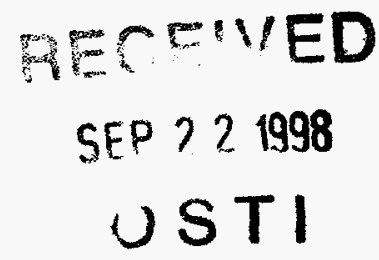

This report was prepared as an account of work sponsored by an agency of the United States Government. Neither the United States Government nor any agency thereof, nor any of their employees, makes any warranty, express or implied, or assumes any legal liability or responsibility for the accuracy, completeness, or usefulness of any information, apparatus, product, or process disclosed, or represents that its use would not infringe privately owned rights. Reference herein to any specific commercial product, process, or service by trade name, trademark, manufacturer, or otherwise does not necessarily constitute or imply its endorsement, recommendation, or favoring by the United States Government or any agency thereof. The views and opinions of authors expressed herein do not necessarily state or reflect those of the United States Government or any agency thereof. 


\section{DISCLAIMER}

Portions of this document may be illegible electronic image products. Images are produced from the best available original document. 
TABLE OF CONTENTS

1.0 PROJECT OBJECTIVES, SCOPE AND DESCRIPTION OF TASKS $\ldots \ldots \ldots \ldots \ldots 1$

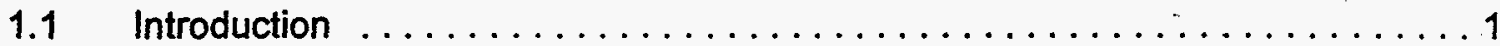

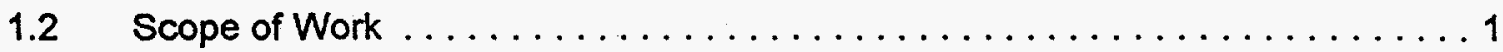

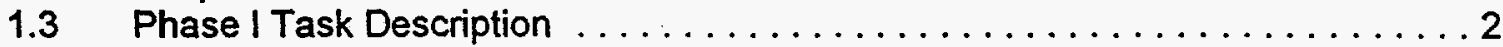

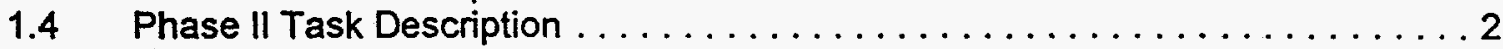

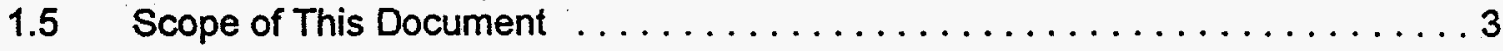

2.0 SUMMARY OF WORK DONE DURING THIS REPORTING PERIOD $\ldots \ldots \ldots \ldots \ldots 4$

2.1 Summary of Major Accomplishments $\ldots \ldots \ldots \ldots \ldots \ldots \ldots \ldots \ldots$

2.2 Chronological Listing of Significant Events in This Quarter ............ 4

3.0 TO DATE ACCOMPLISHMENTS $\ldots \ldots \ldots \ldots \ldots \ldots \ldots \ldots \ldots \ldots \ldots \ldots \ldots \ldots \ldots \ldots \ldots$

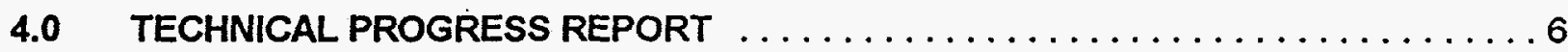

4.1 Laboratory Evaluation of Expanded Slag III for Masonry Block Application . . . .6

4.2 Laboratory Evaluation of SLA III for Roof Tile Application .............6

4.3 Evaluation of SLA in Production of Cement Panels (Waterproof Boards) $\ldots .88$

5.0 PLAN FOR THE NEXT QUARTER $\ldots \ldots \ldots \ldots \ldots \ldots \ldots \ldots \ldots$ 


\subsection{PROJECT OBJECTIVES, SCOPE AND DESCRIPTION OF TASKS}

\subsection{Introduction}

The integrated-gasification combined-cycle (IGCC) process is an emerging technology that utilizes coal for power generation and production of chemical feedstocks. However, the process generates large amounts of solid waste, consisting of vitrified ash (slag) and some unconverted carbon. In previous projects, Praxis investigated the utilization of "as-generated" slags for a wide variety of applications in road construction, cement and concrete production, agricultural applications, and as a landfill material. From these studies, we found that it would be extremely difficult for "asgenerated" slag to find large-scale acceptance in the marketplace even at no cost because the materials it could replace were abundantly available at very low cost. It was further determined that the unconverted carbon, or char, in the slag is detrimental to its utilization as sand or fine aggregate. It became apparent that a more promising approach would be to develop a variety of value-added products from slag that meet specific industry requirements. This approach was made feasible by the discovery that slag undergoes expansion and forms a lightweight material when subjected to controlled heating in a kiln at temperatures between 1400 and $1700^{\circ} \mathrm{F}$. These results confirmed the potential for using expanded slag as a substitute for conventional lightweight aggregates (LWA). The technology to produce lightweight and ultra-lightweight aggregates (ULWA) from slag was subsequently developed by Praxis with funding from the Electric Power Research Institute (EPRI), Illinois Clean Coal Institute ( $\mathrm{ICCl}$ ), and internal resources.

The major objectives of the subject project are to demonstrate the technical and economic viability of commercial production of LWA and ULWA from slag and to test the suitability of these aggregates for various applications. The project goals are to be accomplished in two phases: Phase I, comprising the production of LWA and ULWA from slag at the large pilot scale, and Phase II, which involves commercial evaluation of these aggregates in a number of applications.

Primary funding for the project is provided by DOE's Federal Energy Technology Center (FETC) at Morgantown, with significant cost sharing by Electric Power Research Institute (EPRI) and Illinois Clean Coal Institute ( $\mathrm{ICCl}$ ).

\subsection{Scope of Work}

The Phase I scope consisted of collecting a 20-ton sample of slag (primary slag), processing it for char removal, and pyroprocessing it to produce expanded slag aggregates of various size gradations and unit weights, ranging from 12 to $50 \mathrm{lb} / \mathrm{ft}^{3}$. In Phase $\mathrm{II}$, the expanded slag aggregates are being tested for their suitability in manufacturing precast concrete products (e.g., masonry blocks and roof tiles) and insulating concrete, first at the laboratory scale and subsequently in commercial manufacturing plants. These products will be evaluated using ASTM and industry test methods. Technical data generated during production and testing of the products will be used to assess the overall technical viability of expanded slag production. Relevant cost data for physical and pyroprocessing of slag to produce expanded slag aggregates will be gathered for comparison with (i) the management and disposal costs for slag or similar wastes and (ii) production costs for conventional materials which the slag aggregates would replace. In addition, a market assessment will be made to evaluate the economic viability of these utilization technologies. 


\subsection{Phase I Task Description}

A summary of the tasks performed in Phase I is given below:

Task 1.1 Laboratory and Economic Analysis Plan Development: Development of a detailed work plan for Phase I and an outline of the Phase II work.

Task 1.2 Production of Lightweight Aggregates from Slag: This task covered selection and procurement of project slag samples, slag preparation including screening and char removal, and slag expansion in a direct-fired kiln and fluid bed expander. The char recovered from the slag preparation operation was evaluated for use as a kiln fuel and gasifier feed. Environmental data for slag-based lightweight aggregate (SLA) production was collected.

Task 1.3 Data Analysis of Slag Preparation and Expansion: Analysis and interpretation of project data, including development of material and energy balances for slag processing and product evaluation.

Task 1.4 Economic Analysis of Expanded Slag Production: Economic analysis of the utilization of expanded slag was conducted by determining production costs for slag-based LWAs and ULWAs. Expanded slag production costs were compared with the market value of similar products both with and without taking into account the avoided costs of disposal and with the costs of management of slag as a solid waste.

Task 1.5 Topical and Other Reports: Preparation topical, financial status, and technical progress reports in accordance with the Statement of Work.

\subsection{Phase II Task Description}

A summary of the tasks to be performed in Phase II is given below.

Task 2.1 Test Plan for Applications of Expanded Slags (Field Studies): This task involves the development of selection criteria and a field test plan for applications of expanded slag. This plan will serve as a guide in the selection and implementation of field demonstrations for the most promising expanded slag utilization applications. Field applications will be selected on the basis of laboratory results, the marketability of the products, and the suitability of the project slags for producing them. The following applications are under consideration for testing:

- Lightweight concrete blocks made from $50 \mathrm{lb} / \mathrm{ft}^{3}$ SLA

- Lightweight roof tiles made from $40 \mathrm{lb} / \mathrm{ft}^{3} \mathrm{SLA}$

- Loose fill insulation made from $16 \mathrm{lb} / \mathrm{ft}^{3} \mathrm{SLA}$

- Lightweight insulating concrete made from $16 \mathrm{lb} / \mathrm{ft}^{3} \mathrm{SLA}$

Task 2.2 Field Studies to Test Expanded Slag Utilization: Under this task, field testing of the applications identified in Phase $\|_{1}$. Task 2.1, will begin with test work to optimize the concrete mixes made from expanded slag. 
Task 2.3 Data Analysis of Commercial Utilization of Expanded Slags: The objective of this task is to assimilate the data and test results collected during Phase II, Task 2.2, convert these findings to common engineering terms, and correlate these results with comparable information for conventional lightweight aggregates as reported in the literature. The data analysis will provide specific answers to the following issues:

- Performance of expanded slag compared with that of conventional materials

- Technical viability of lightweight and ultra-lightweight slags as aggregates.

Task 2.4 Economic Analysis of Expanded Slag Utilization: The objective of this task is to expand upon the preliminary economic assessment of expanded slag utilization conducted during Phase I. The economics will be studied based on the production costs for SLA in comparison with current market prices for conventional materials. During the Phase I preliminary evaluation, two production scenarios emerged:

- Production of SLA at the gasifier location (on-site production)

- Production of SLA at a lightweight aggregate facility (off-site production).

The impact of the avoided costs of slag disposal on the economics of SLA production will also be evaluated. Slag utilization data and product samples will be made available to commercial lightweight aggregate users for validation of estimated market prices. The impact of SLA market prices on the economics of SLA production will also be studied.

Task 2.5 Final Report: The data generated and collected during the project will be compiled in a final report to be submitted at the end of the project that will be a comprehensive description of the results achieved, consistent with the Reporting Requirements. Data from topical and field reports will be summarized. The report will include the original hypothesis of the project and present the investigative approaches used, complete with problems encountered or departures from the planned methodology, and an assessment of their impact on the project results.

\subsection{Scope of This Document}

This is the fifteenth quarterly report and summarizes the work undertaken during the performance period between 1 March 1998 and 31 May 1998. It is the eighth quarterly report for Phase II. This document summarizes the Phase II accomplishments to date along with the major accomplishments from Phase I. 


\subsection{SUMMARY OF WORK DONE DURING THIS REPORTING PERIOD}

\subsection{Summary of Major Accomplishments}

In the current reporting period, test work focused on Slag III lightweight aggregates. The following was accomplished during this reporting period:

1. Laboratory testing of expanded Slag III for the lightweight block application was completed satisfactorily. The block production run has been scheduled for 11 June 1998.

2. Testing of expanded Slag III made from 50/50 Slag III/clay for the roof tile application was completed satisfactorily. Specimens with a strength of over 5,600 psi were produced.

3. Commercial production and economic evaluation of the expanded slag in panel application was initiated per user request.

4. Additional batch testing for nursery applications has been initiated.

\subsection{Chronological Listing of Significant Events in This Quarter}

The following significant events occurred during the current reporting period:

\begin{tabular}{|l|l|}
\hline \multicolumn{1}{|c|}{ Date } & \multicolumn{1}{c|}{ Description } \\
\hline $3 / 12 / 98$ & Testing of Tampa Electric slag (Slag IV) included in the currect project \\
\hline $3 / 23 / 98$ & Roof tile evaluation of expanded slag/clay 50/50 blends was reconfirmed \\
\hline $4 / 25 / 98$ & $\begin{array}{l}\text { Commercial production and economic evaluation of expanded slag in panel } \\
\text { application was initiated per user request }\end{array}$ \\
\hline
\end{tabular}

\subsection{TO DATE ACCOMPLISHMENTS}

A summary of the work completed in Phase 1 is given below.

\begin{tabular}{||l|l||}
\hline Date & \multicolumn{1}{|c|}{ Phase I Accomplishments Description } \\
\hline $10 / 24 / 94$ & Draft Laboratory and Economic Analysis Plan (project work plan) submitted \\
\hline $11 / 18 / 94$ & $\begin{array}{l}\text { Slag char removal completed on the advance sample and prepared slag } \\
\text { laboratory expansion testing initiated }\end{array}$ \\
\hline $12 / 02 / 94$ & Final "Laboratory and Economic Analysis Plan" prepared and submitted \\
\hline $05 / 21 / 95$ & Primary slag sample (20 ton) received at Penn State for preparation \\
\hline $06 / 01 / 95$ & Pilot unit for char removal set up and processing work started \\
\hline $08 / 20 / 95$ & Primary slag sample processing for char removal completed \\
\hline $9 / 10 / 95$ & Laboratory expansion studies of slag and slag/clay blends started \\
\hline $10 / 15 / 95$ & 1-ft and 3-ft diameter kilns commissioned for pilot testing \\
\hline $11 / 15 / 95$ & Pilot testing of Slag I and Slag II and pellets in 3-ft dia. direct-fired kiln completed \\
\hline $11 / 17 / 95$ & Pilot testing using fluidized bed expander completed \\
\hline $12 / 12 / 95$ & SLA product characterization initiated \\
\hline $1 / 20 / 96$ & Laboratories for testing of SLA products identified \\
\hline $2 / 16 / 96$ & Test plan for second batch of fluid bed expander testing at Fuller completed \\
\hline
\end{tabular}


A summary of the work completed in Phase $\|$ to date is given below.

\begin{tabular}{|c|c|}
\hline Date & Phase II Accomplishments Description \\
\hline $4 / 30 / 96$ & Application for continuation of the project to Phase II submitted \\
\hline $5 / 31 / 96$ & Phase I Final Report (draft) submitted to METC \\
\hline $7 / 1 / 96$ & Phase I Topical Report (final version) submitted \\
\hline $7 / 14 / 96$ & Approval for continuation of the project to Phase II was received from METC \\
\hline $7 / 14 / 96$ & Structural concrete laboratory tests started \\
\hline $7 / 15 / 96$ & Lab testing of SLA for roof tile and insulating concrete applications completed \\
\hline $7 / 15 / 96$ & Evaluation of SLA for completed \\
\hline $7 / 30 / 96$ & Evaluation of SLA for loose fill insulation completed \\
\hline $10 / 10 / 96$ & Mix designs for block production selected \\
\hline $11 / 10 / 96$ & Laboratory evaluation of the Slag II completed \\
\hline $10 / 30 / 96$ & Structural concrete laboratory tests completed \\
\hline $11 / 10 / 96$ & Laboratory evaluation of Slag III for LWA production completed \\
\hline $1 / 10 / 97$ & Laboratory testing of SLA for structural concrete application completed \\
\hline 2/19/97 & First batch of laboratory tests of selected block mixes completed \\
\hline $4 / 30 / 97$ & Processing of Slag III for char removal completed \\
\hline $5 / 20 / 97$ & Preparatory work for Slag III pyroprocessing completed \\
\hline $7 / 30 / 97$ & Preparation of Slag III for SLA production completed \\
\hline $8 / 20 / 97$ & Utilization of SLA as growing medium for potted plants completed successfully \\
\hline $10 / 2 / 97$ & Exploratory testing of expanded slag for nursery applications completed \\
\hline $10 / 2 / 97$ & Laboratory testing of expanded Slag I for block application completed \\
\hline $11 / 1 / 97$ & Testing of expanded slag in panel application completed \\
\hline $12 / 2 / 97$ & Second phase of testing of expanded slag for nursery applications started \\
\hline $1 / 20 / 98$ & Evaluation of expanded Slag III for block and roof tile applications initiated \\
\hline $2 / 15 / 98$ & $\begin{array}{l}\text { Second round evaluation of expanded Slag III in panel application completed by } \\
\text { end user }\end{array}$ \\
\hline $3 / 12 / 98$ & Testing of Tampa Electric slag (Slag IV) included in the currect project \\
\hline $3 / 23 / 98$ & Roof tile evaluation of expanded slag/clay $50 / 50$ blends was reconfirmed \\
\hline $4 / 25 / 98$ & $\begin{array}{l}\text { Commercial production and economic evaluation of expanded slag in panel } \\
\text { application was initiated per user request }\end{array}$ \\
\hline
\end{tabular}




\subsection{TECHNICAL PROGRESS REPORT}

\subsection{Laboratory Evaluation of Expanded Slag III for Masonry Block Application}

In order to verify the utilization applications developed for other slags, SLA III was used to make concrete for lightweight blocks. The primary objective of these tests was to improve the compressive strength of the blocks. Test mixes were formulated, based on our experience with the previous batch of Slag III, in order to manufacture two types of blocks:

1. Regular-weight blocks with a dry weight of approximately $33.5 \mathrm{lb}$ (150 lb/ft ${ }^{3}$ concrete)

2. Lightweight blocks with a dry weight of approximately $27 \mathrm{lb}\left(115 \mathrm{lb} / \mathrm{ft}^{3}\right.$ concrete)

For both block mixes, the conventional lightweight aggregate was replaced by fine. SLA III made from a $10 \times 50 \mathrm{M}$ Slag III feed (SLA III-F). The cement-to-aggregate ratio used was identical to that currently used at the block manufacturing plant.

The previous compressive strength values were below 2000 psi. One test (LB-7) was performed to increase the strength to 2000 psi by using a slightly higher quantity of cement. The results are given below.

\begin{tabular}{|c|c|c|c|c|c|c|c|}
\hline $\begin{array}{c}\text { Test } \\
\text { ID }\end{array}$ & $\begin{array}{c}\text { Type I } \\
\text { Cement }\end{array}$ & $\begin{array}{c}\text { SLA III } \\
10 \times 50 M\end{array}$ & $\begin{array}{c}\text { Unwashed } \\
\text { Sand }\end{array}$ & $\begin{array}{c}\text { Mighty } \\
150(\mathrm{ml})\end{array}$ & $\begin{array}{c}\text { Unit Wt. } \\
\left(\mathrm{lb} / \mathrm{ft}^{3}\right)\end{array}$ & $\begin{array}{c}\text { 7-Day } \\
\text { Strength } \\
\text { (psi) }\end{array}$ & $\begin{array}{c}\text { 28-Day } \\
\text { Strength } \\
\text { (psi) }\end{array}$ \\
\hline LB-7 & 658 & 1616.4 & 2343.6 & 13.5 & 108 & 1531 & 1998 \\
\hline
\end{tabular}

As may be seen, the unit weight of the concrete specimens was $108 \mathrm{lb} / \mathrm{ft}^{3}$ and the compressive strength was nearly 2000 psi. Analysis of the mix indicated that in spite of the addition of sand, it was deficient in minus 100-mesh fines. Based on this assessment, we decided to produce a mix with $10 \%$ additional fines in the form of a mineral filler. We will then produce a batch of blocks in the block manufacturing machine. The production run has been scheduled for 11 June 1998.

\subsection{Laboratory Evaluation of SLA III for Roof Tile Application}

The objective of this test program was to produce higher-strength lightweight concrete suitable for the roof tile application. For this purpose, we granulated unexpanded Slag III/clay pellets to a nominal 4 mesh size prior to expansion. The compressive strength requirements for this application are in the $2500-4000$ psi range, with corresponding unit weights in the $115-105 \mathrm{lb}_{\mathrm{ft}}{ }^{3}$ range. Previous evaluations (RT-1 and RT-2) conducted for this application showed very high strengths. The objective of the current batch of testing was to study the mix designs further and verify the high compressive strengths by repeating the tests.

Evaluation of the data and visual examination of the previous samples indicated that they were deficient in fines. Therefore, the original tests (RT-1 and RT-2) and the repeat tests RT-3 and RT-4 were performed using Slag III/clay along with large quantities of fines generated during the production of the same product. The roof tile aggregate mixes for tests RT-1 and RT-3 used $75 \%$ fines and those for tests RT-2 and RT-4 used $50 \%$ fines. The expanded fines were added to provide continuity in the gradation of the aggregate and cement. The particle size distribution of the expanded Slag III/clay blend is given in Table 1. 
Table 1. Size Gradation of Aggregate Mix Used in Roof Tile Tests

\begin{tabular}{|l|c|c|c|c|}
\hline Size & $\begin{array}{c}\text { Coarse Aggregate } \\
\text { Slag III/Clay }\end{array}$ & $\begin{array}{c}\text { Fine Aggregate } \\
\text { Cyclone Fines }\end{array}$ & RT-3 Mix & RT-4 Mix \\
\hline & $10 \times 50 \mathrm{M}$ & & $25 / 75^{\star}$ & $50 / 50^{*}$ \\
\hline $4 \times 8 \mathrm{M}$ & Wt\% & Wt\% & & \\
\hline $8 \times 16 \mathrm{M}$ & 0.1 & 53.0 & 39.8 & 46.4 \\
\hline $16 \times 30 \mathrm{M}$ & 1.3 & 40.6 & 30.8 & 35.7 \\
\hline $30 \times 50 \mathrm{M}$ & 18.6 & 6.4 & 9.5 & 7.9 \\
\hline $50 \times 100 \mathrm{M}$ & 13.1 & 0.0 & 3.3 & 1.6 \\
\hline $100 \times 200 \mathrm{M}$ & 9.4 & 0.0 & 2.4 & 1.2 \\
\hline $200 \mathrm{M} \times 0$ & 10.9 & 0.0 & 2.7 & 1.4 \\
\hline & 46.6 & 0.0 & 11.7 & 5.8 \\
\hline
\end{tabular}

*Proportion of expanded Slag III/clay vs. cyclone fines.

The roof tile concrete mixes were prepared using the same procedure as was used for the previous batch of tests (RT-1 and RT-2):

Aggregate mix evaluated

Superplasticizer:

Accelerator:

Aggregate-to-cement ratio (by weight):

Water-to-cement ratio:
$10 \times 50 \mathrm{M}$ Slag III/clay $50 / 50$ mixed with fines $2.0 \mathrm{ml} / 100 \mathrm{~g}$ cement (Mighty 150) for all tests $2 \%$ by weight $\left(\mathrm{CaCl}_{2} \cdot 2 \mathrm{H}_{2} \mathrm{O}\right)$ where indicated

2.5

to obtain 0-1 slump

Three 2" $\times 2^{\prime \prime} \times 2^{\prime \prime}$ mortar cubes were cast using the concrete, cured in a wet box (relative humidity of $\sim 70 \%$ ) for 2 hours, and then steam-cured at $\sim 60^{\circ} \mathrm{C}$ for 4 hours. The cubes were demolded and retumed to the wet box for further curing to 7 days. The cubes were then weighed and broken in compression. A summary of the formulations and 7-day compressive strengths is presented in Table 2. The highest 7-day compressive strength for the SLA III specimens was 5600 psi, which is considerably higher than the previous best results of 2800 psi for SLA I and exceeds the ASTM requirement of $4000 \mathrm{psi}$. One reason for these good results is that the baghouse dust fines were added to the SLA III aggregate in the mix. The unit weights of the specimens made from SLA III ranged between 113.6 and $114.6 \mathrm{lb} / \mathrm{ft}^{3}$. 
Table 2. Evaluation of SLA III as Aggregate in Roof Tile Application

\begin{tabular}{|c|c|c|c|c|c|c|}
\hline \multirow[t]{2}{*}{ Test No } & \multicolumn{2}{|c|}{ AggregateFines } & \multirow{2}{*}{$\begin{array}{c}\text { Water/ } \\
\text { Cement } \\
\text { Ratio }\end{array}$} & \multirow{2}{*}{$\begin{array}{l}\text { Mortar } \\
\text { Unit Wt } \\
\left(\mathrm{lb} / \mathrm{ft}^{3}\right)\end{array}$} & \multicolumn{2}{|c|}{$\begin{array}{l}\text { Compressive } \\
\text { Strength (psi) }\end{array}$} \\
\hline & Coarse & Fines & & & 7-day & 28-day \\
\hline \multicolumn{7}{|c|}{ Slag III/Clay 50/50 aggregate blended with fines } \\
\hline RT-3 & 25 & 75 & 0.57 & 104.4 & 5043 & 5902 \\
\hline RT -4 & 50 & 50 & 0.47 & 107.2 & 6801 & 6991 \\
\hline RT-1 & 25 & 75 & 0.57 & 113.6 & 5598 & 5603 \\
\hline RT-2 & 50 & 50 & 0.47 & 114.6 & 5603 & 6421 \\
\hline \multicolumn{7}{|c|}{ Other Aggregates } \\
\hline SLA I** & 100 & - & 0.35 & 93.3 & 2806 & 2823 \\
\hline $\begin{array}{l}\text { Roof tile plant } \\
\text { LWA (control) }\end{array}$ & 100 & - & 0.45 & 105.3 & 3390 & 4789 \\
\hline Slag I/Clay** & 100 & - & 0.35 & 105.2 & 2303 & 2808 \\
\hline
\end{tabular}

** Tests conducted with SLA I and commercial aggregate used by the roof tile manufacturer were done previously using plasticizer ( $2 \%$ by weight of cement) and $\mathrm{CaCl}_{2} \bullet \mathrm{H}_{2} \mathrm{O}$.

Note: Tests RT-1, RT-2, RT-3 and RT-4 were done using a 50/50 mixture of expanded Slag III and clay with only plasticizer ( $2 \%$ by weight of cement).

As may be seen in Table 2, the Slag III/clay mixes (RT-3 and RT-4) resulted in compressive strengths of 5600-6400 psi with corresponding unit weights of $114-115 \mathrm{lb} / \mathrm{ft}^{3}$. These results have been provided to the roof tile manufacturer, and we have begun discussions on potential testing to produce roof tiles.

\subsection{Evaluation of SLA in Production of Cement Panels (Waterproof Boards)}

Based on evaluation of the results using SLA to make insulating concrete, another similar application was identified: production of lightweight cement concrete panels used in the construction of bathrooms and other areas where walls are exposed to moisture. This is a relatively new but fast growing application that requires $35-45 \mathrm{lb} / \mathrm{ft}^{3}$ aggregates. Praxis contacted a manufacturer and sent samples of SLA I to them for laboratory evaluation. Exploratory tests indicated that SLA could be used a substitute for conventional lightweight aggregates to make these panels. Two 55-gallon drum samples of $10 \times 50 \mathrm{M}$ SLA III were supplied to the manufacturer, along with cyclone fines. One of the drums contained 35-40 $\mathrm{lb} / \mathrm{ft}^{3}$ SLA, and the other contained $40-45 \mathrm{lb} / \mathrm{ft}^{3}$ SLA.

The tests have been scheduled for 19 June 1998.

Work is currently in progress at both Fuller and Praxis to estimate the capacity and operating costs for producing LWA for the panel application at the manufacturer's facility. 


\subsection{PLAN FOR THE NEXT QUARTER}

The following activities are planned for the next quarter:

- Commercial-scale block-making production run has been scheduled for 11 June 1998.

- Continue laboratory evaluation of SLA I for horticultural applications.

- Complete laboratory evaluation of the SLA for concrete panel applications at the commercial manufacturing plant.

- Reevaluate SLA III/clay for the roof tile application with manufacturers in order to have them evaluate a large sample of SLA for this application. 